\title{
Activation of Jun Kinase Is an Early Event in Hepatic Regeneration
}

\author{
J. K. Westwick, ${ }^{\star t \$}$ C. Weitzel, ${ }^{\star \S}$ H. L. Leffert," and D. A. Brenner* \\ * Departments of Medicine, Biochemistry and Biophysics, University of North Carolina, Chapel Hill, North Carolina 27599-7038; and \\ ${ }^{\ddagger}$ Program in Molecular Pathology and "Department of Pharmacology and Center for Molecular Genetics, University of California, \\ San Diego, La Jolla, California 92093
}

\begin{abstract}
Compensatory hepatic regeneration after partial hepatectomy (PH) is dependent upon the extent of resection. This study analyzes the regulation of the AP-1 transcription factor c-Jun during hepatic regeneration. There is a progressive increase in c-jun mRNA levels after sham operation, one-third PH, and two-thirds PH. A concomitant increase in AP-1 binding activity is also observed. The c-Jun protein is a major constituent of the AP-1 complex in quiescent and early regenerating liver. The activity of c-Jun nuclear kinase (JNK), which phosphorylates the activation domain of the c-Jun protein, is markedly stimulated after one-third PH. JNK1 or an immunologically related kinase is a constituent of this stimulated JNK activity after PH. When primary cultures of adult rat hepatocytes are incubated with epidermal growth factor or transforming growth factor- $\alpha$, AP-1 transcriptional activity is increased and the activation domain of the c-Jun protein is further potentiated. Phosphopeptide mapping of the endogenous c-Jun protein in proliferating cultured hepatocytes demonstrates phosphorylation of the c-Jun activation domain. Combining the results of these in vivo and culture studies, we conclude that the minimal stimulation of one-third PH activates JNK, which phosphorylates the c-Jun activation domain in hepatocytes, resulting in enhanced transcription of AP-1-dependent genes. (J. Clin. Invest. 1995. 95:803-810.) Key words: hepatic regeneration - transcription - c-Jun - signal transduction • kinase $\cdot$ proliferation

\section{Introduction}

Hepatocytes of normal adult liver divide infrequently. Immediately after partial hepatectomy $(\mathrm{PH}),{ }^{1}$ however, there is a sequential and regulated series of events as the quiescent hepatocytes progress in the cell cycle from $G_{0}$ to $G_{1}(1-4)$. These include increased sodium ion influx (5) and induction of protooncogene expression. The early response genes that are in-

Address correspondence to Dr. D. A. Brenner, Department of Medicine, CB\#7080, University of North Carolina, Chapel Hill, NC 27599-7080. Phone: 919-966-2511; FAX: 919-966-6842; e-mail: dab@med.unc.edu. 1994.

Received for publication 1 July 1994 and in revised form 25 October

1. Abbreviations used in this paper: EGF, epidermal growth factor; ERK, extracellular signal-regulating kinase; JNK, c-Jun nuclear kinase; PH, partial hepatectomy; SAPK, stress-activated protein kinase; TGF $\alpha$, transforming growth factor- $\alpha$.

J. Clin. Invest.

(C) The American Society for Clinical Investigation, Inc.

0021-9738/95/02/0803/08 \$2.00

Volume 95, February 1995, 803-810 duced include c-fos, c-jun, Jun B, LRH-1, and c-myc (1-4, 68 ). The induction of DNA synthesis and early response gene and protein expression is proportional to the extent of $\mathrm{PH}$ $(9,10)$.

The products of the $j u n$ and fos family of genes are components of the transcription factor AP-1 $(11,12)$. The expression of c-Jun is required for liver development, as demonstrated by failure of hepatic development in a c-jun knock-out mouse (13). The induction of c-jun mRNA after PH is independent of de novo protein synthesis (1), and the c-jun gene is regulated by autostimulation of its AP-1-binding site by the c-Jun protein (14).

The transcriptional activity of the c-Jun protein is regulated by its phosphorylation status. Phosphorylation of the carboxyterminal c-Jun region near its DNA-binding site inhibits DNA binding and therefore transcriptional activity $(15,16)$. However, phosphorylation of the c-Jun amino-terminal transcription activation domain at Ser-63 and Ser-73 enhances transcriptional activity (17-19). Phosphorylation of the amino-terminal domain is catalyzed by a c-Jun nuclear kinase, JNK, which has been purified, and some of its constituents have been cloned (20-22). Two-thirds $\mathrm{PH}$ in rats induces a marked stimulation of c-jun mRNA levels as well as DNA synthesis $(9,23)$. We have recently demonstrated that this activity is accompanied by an early increase in JNK activity (24). These changes can be simulated by treatment of quiescent hepatocyte cultures with transforming growth factor- $\alpha$ (TGF $\alpha)$ (25).

We now demonstrate a proportional increase in JNK activity in the liver after sham operation, one-third PH, and two-third $\mathrm{PH}$. There is also a proportional increase in c-jun mRNA levels and AP-1 activity. Furthermore, in primary cultures of adult rat hepatocytes, mitogens stimulate AP-1 transcriptional activity and specifically stimulate the activity of the c-Jun activation domain. Therefore, one of the earliest events after one-third $\mathrm{PH}$ (this study) or two-thirds PH (24) is the induction of JNK activity, which might be required for subsequent steps in hepatocyte proliferation.

\section{Methods}

Reagents and tissue culture media. All reagents are from Sigma Chemical Co. (St. Louis, MO) unless otherwise specified. All tissue culture media were from Gibco BRL (Gaithersburg, MD). FBS was from Gemini Biosciences (Calabassas, CA). Receptor-grade murine epidermal growth factor (EGF) was from Sigma Chemical Co. Collagen type IV was obtained from Collaborative Research (Bedford, MA). Percoll was obtained from Pharmacia (Piscataway, NJ). Free fatty acids were from NuChek (Elysian, MN). Polyclonal rabbit anti-c-Fos antiserum was purchased from Santa Cruz Biotechnology (Santa Cruz, CA). c-Junspecific antiserum was provided by A. Kraft, University of Alabama. Antiserum raised against recombinant JNK1 was provided by M. Karin, University of California, San Diego.

Plasmids. RSVcJun contains the coding sequence of human c-jun 5XGal-Luc contains five repeats of the Gal4 DNA-binding site linked to the luciferase reporter gene. Eukaryotic expression vector Gal4-cJun 
consists of the Gal4 DNA-binding domain linked to the c-Jun transcriptional activation domain (amino acids 1-246). Gal4-cJun(AA) has Ser-63 and Ser-73 mutated to Ala (20). Prokaryotic expression vectors GST-cJun (amino acids 1-223 of c-Jun linked to the GST protein), GST-cJun(AA) (with Ser-63 and Ser-73 mutated to alanines), and the parental GST expression vector have been previously described (20). The 2XTRE-Luc reporter (gift of K. Chien, University of California, San Diego) contains four repeats of the consensus AP-1-binding site linked to the minimal prolactin TATA box and the luciferase reporter gene. Jun-Luc contains the human c-jun promoter from Jun-CAT (12, 14) linked to the luciferase reporter gene of P19-Luc.

Partial hepatectomy. The protocols for this study were approved by the Department of Laboratory Animal Medicine at the University of North Carolina, Chapel Hill, and at the University of California, San Diego. Experiments were carried out in compliance with National Institutes of Health guidelines on the care and use of laboratory animals. Male Sprague-Dawley rats (200-225 g; Harlan, Indianapolis, IN) were anesthetized with $100 \mathrm{mg} / \mathrm{kg}$ ketamine, $2.5 \mathrm{mg} / \mathrm{kg}$ acepromazine, and $2 \mathrm{mg} / \mathrm{kg}$ lidocaine. In control animals $(\mathrm{C} 0$ or $\mathrm{T}=0)$, total hepatectomy was performed immediately after anesthesia. For sham-operated animals, the liver was exposed by a median abdominal incision; for onethird or two-thirds PH, the left liver lobe or the left and median lobes, respectively, were ligated centrally. The unperfused liver tissue was removed, and the incision was closed with sutures. The rats were allowed to recover from anesthesia under observation. At various time points after ligation ( $20 \mathrm{~min}$, or $1,2,12$, or $24 \mathrm{~h}$ ), the remaining liver tissue was removed and nuclear extracts or RNA was prepared.

RNA isolation and Northern blotting. Isolation of total hepatic RNA was performed as previously described (26). RNA samples $(25 \mu \mathrm{g})$ were electrophoresed on $2.2 \mathrm{M}$ formaldehyde-1\% agarose gels, and transferred to a nylon membrane (MSI, Westboro, MA). Equal loading of RNA was confirmed by ethidium bromide staining of the gels. RNA was ultraviolet cross-linked to the membrane, and blots were probed with the following random-primed gene fragments: a 1-kb HindIII-PstI fragment of RSVcJun (14), a 0.8-kb PstI fragment of murine c-fos (27), a 1-kb HindIII fragment of rat serum albumin (28), and a 1.4kb HindIII-Xbal fragment of pCMV-Flag-JNK1 (21) (provided by M. Karin). Final wash stringency was $0.1 \times$ SSC, $0.1 \%$ SDS at $60^{\circ} \mathrm{C}$.

Nuclear extracts and recombinant proteins. Nuclear extracts were prepared as described (29) with the inclusion of protease and phosphatase inhibitors at all steps as follows: $0.1 \mathrm{mM}$ PMSF, $2.0 \mu \mathrm{g} / \mathrm{ml}$ aprotinin, $2 \mu \mathrm{g} / \mathrm{ml}$ leupeptin, $2 \mu \mathrm{g} / \mathrm{ml}$ bestatin, $0.7 \mu \mathrm{g} / \mathrm{ml}$ pepstatin, $20 \mathrm{mM}$ $\beta$-glycerophosphate, $50 \mu \mathrm{M} \mathrm{Na}_{3} \mathrm{VO}_{4}, 10 \mathrm{mM} \mathrm{Na}_{3} \mathrm{MoO}_{4}, 10 \mathrm{mM} \mathrm{NaF}$, $10 \mathrm{mM} p$-nitrophenylphosphate. Protein induction and purification in the BL-21 strain of Escherichia coli (Novagen, Madison, WI) were performed as described (30). Concentrations were determined by protein assay (Bio-Rad Laboratories, Hercules, CA), and nuclear extracts were stored under liquid nitrogen.

Gel mobility shift assays. Determination of specific shifted complexes was determined using a consensus AP-1 site (5'-TAAAGCATGAGTCAGGACACCTC-3') from the human collagenase gene as probe (11) or the HNF-1-binding site (5'-TGTGGTTAATGATCTACAGTTA- $\left.3^{\prime}\right)$ from the rat serum albumin gene $(11,31)$. Probes were labeled by reaction with $\mathrm{T} 4$ polynucleotide kinase (New England Biolabs, Beverly, MA) and $\left[\gamma-{ }^{32} \mathrm{P}\right]$ ATP. Binding reactions were performed with $10 \mu \mathrm{g}$ of nuclear extract for $20 \mathrm{~min}$ at room temperature, and electrophoresis was as described previously (26) with a 1,000 -fold excess of poly $(\mathrm{dI} / \mathrm{dC})$. Where indicated, $0.5 \mu \mathrm{l}$ of polyclonal rabbit antiserum specific for c-Jun, or $1 \mu \mathrm{l}$ of anti-c-Fos polyclonal rabbit antisera or preimmune rabbit serum, was included for the final $15 \mathrm{~min}$ of the incubation at $37^{\circ} \mathrm{C}$. Shifted complexes on $4 \%$ nondenaturing polyacrylamide gels were visualized by autoradiography.

Jun kinase assays. In vitro JNK assays were performed as described (20) using purified recombinant GST-cJun, a mutated GST-cJun with Ser-63 and Ser-73 mutated to ala (GST-cJUN(AA)), or GST protein alone as substrate. Substrates $(10 \mu \mathrm{g}$ attached to glutathione-agarose beads) were incubated with $50 \mu \mathrm{g}$ of nuclear extract, washed extensively in buffer containing $0.5 \%$ Triton X-100, incubated with $\left[\gamma-{ }^{32} \mathrm{P}\right] \mathrm{ATP}$ $(4,000-10,000 \mathrm{Ci} / \mathrm{mmol})$ and $40 \mu \mathrm{M} \mathrm{ATP}$ for $20 \mathrm{~min}$ at $30^{\circ} \mathrm{C}$. These were then washed and electrophoresed on $10 \%$ SDS-polyacrylamide gels. The single prominent band on these gels represents phosphorylated GST-cJun. The relative mass was confirmed by comparison with protein molecular weight standards. For the JNK immune complex kinase assays, $50 \mu \mathrm{g}$ of nuclear extract was incubated with antiserum raised against JNK1, and immune complexes were collected with protein Aplus/protein G-agarose (Oncogene Science, Uniondale, NY). After washing extensively with RIPA, PAN $+0.5 \%$ NP-40, and PAN (32), complexes were incubated in kinase buffer (as previously described) containing GST-cJun, GST protein alone, or no substrate. Kinase reactions and electrophoresis were performed as previously described.

Cell isolation and culture. Hepatocytes used in transfection and labeling experiments were isolated by two methods. For primary hepatocytes plated on plastic dishes, cultures were prepared as described previously (33). For plating on collagen-coated plates, hepatocytes were isolated from male Sprague-Dawley rats $(220-225 \mathrm{~g})$ by collagenase perfusion (34). The cell suspension was purified and enriched for viable hepatocytes by centrifugation over Percoll (35) leading to a purity of 98\% hepatocytes and a viability of $93 \%$ as assessed by trypan blue exclusion. The yield ranged from $1.5 \times 10^{8}$ to $2 \times 10^{8}$ cells per liver. After washing the cells twice with DME, the hepatocytes were plated on collagen type IV-coated $35-\mathrm{mm}$ dishes $(0.34 \mu \mathrm{g}$ of collagen per $\mathrm{cm}^{2}$ ) in $2 \mathrm{ml}$ of MEM-S (MEM modified for suspension cultures) containing $0.4 \mathrm{mM}$ calcium, $10 \%$ dialyzed FBS, $2 \mathrm{mM}$ glutamine, 100 $\mu \mathrm{g} / \mathrm{ml}$ gentamycin, $100 \mu \mathrm{g} / \mathrm{ml}$ kanamycin, and $0.5 \mu \mathrm{g} / \mathrm{ml}$ fungizone and cultured in a humidified atmosphere containing $5 \% \mathrm{CO}_{2}$ at $37^{\circ} \mathrm{C}$.

Transfections. Hepatocytes were prepared by collagenase perfusion as previously described, and plated at a density of $1.2 \times 10^{6}$ cells per 35-mm plate in arginine-free DME plus 5\% dialyzed FBS (for cells plated on plastic). Other cells were plated on collagen. $1 \mathrm{~h}$ after plating, the hepatocytes were washed twice with PBS, and the medium was replaced with $1 \mathrm{ml}$ of defined medium containing $0.4 \mathrm{mM}$ calcium, 10 $\mu \mathrm{g} / \mathrm{ml}$ hydrocortisone, $5 \mu \mathrm{g} / \mathrm{ml}$ insulin, $10 \mathrm{ng} / \mathrm{ml} \mathrm{EGF}, 2 \mathrm{mM}$ glutamine, plus antibiotics and antimycotics as previously described. $1 \mathrm{~h}$ later, cells were transfected with $2.5 \mu \mathrm{g}$ of reporter plasmid and $0.5 \mu \mathrm{g}$ of expression vector, as indicated, plus $10 \mu \mathrm{g}$ of Lipofectin reagent (Gibco BRL) per plate. After $5 \mathrm{~h}$, transfection mixtures were removed; cells were washed once with PBS, and media were replaced with $2 \mathrm{ml}$ of defined media as previously described. After $4 \mathrm{~d}$ on plastic, or $1 \mathrm{~d}$ on type IV collagen, EGF $(10 \mathrm{ng} / \mathrm{ml})$ or vehicle alone (PBS) was added to the media. 5 and $24 \mathrm{~h}$ later, for cells on plastic and collagen, respectively, extracts were prepared using enhanced luciferase assay reagents (Analytical Luminescence, San Diego, CA). Luciferase activity was measured on a Monolight 2010 (Analytical Luminescence, San Diego, CA) for $20 \mathrm{~s}$, and all results were normalized for extract protein concentration determined with the Bio-Rad protein assay reagent.

Immunoprecipitation and phosphopeptide mapping. Primary cultures of adult rat hepatocytes were prepared as previously described and plated on plastic dishes at a density of $3.5 \times 10^{6}$ cells per $100-\mathrm{mm}$ plate. $24 \mathrm{~h}$ later, cells were transfected with $10 \mu \mathrm{g}$ of RSVcJun. $24 \mathrm{~h}$ after removal of the transfection mixture, medium was changed to 2.5 $\mathrm{ml}$ of phosphate-free or methionine-free DME. After $30 \mathrm{~min}, 1 \mathrm{mCi}$ of $\left[{ }^{32} \mathrm{P}\right.$ ] orthophosphate or $150 \mu \mathrm{Ci}$ of Trans $-{ }^{35} \mathrm{~S}$-label (ICN Biochemicals, Costa Mesa, CA) was added to the plates; incubation continued for an additional $2.5 \mathrm{~h}$. Where indicated, $10 \mathrm{ng} / \mathrm{ml}$ EGF (murine) was added to the plate for the final $30 \mathrm{~min}$ before lysis of the cells. Cell lysis, immunoprecipitation with c-Jun-specific antisera, and two-dimensional phosphopeptide mapping were performed as previously described (36).

\section{Results}

Total cellular RNA was isolated for Northern blotting from adult rat livers after sham operation, one-third $\mathrm{PH}$, or two-thirds PH. As previously described $(2,6)$, two-thirds $\mathrm{PH}$ results in a transient induction of $\mathrm{c}$-fos (Fig. $1 \mathrm{~A}$ ) and a more prolonged induction of c-jun mRNA (Fig. $1 B$ ). Sham operation and onethird PH result in no detectable c-fos mRNA. However, c-jun mRNA levels are induced a maximum of 16-fold by two-thirds 
A
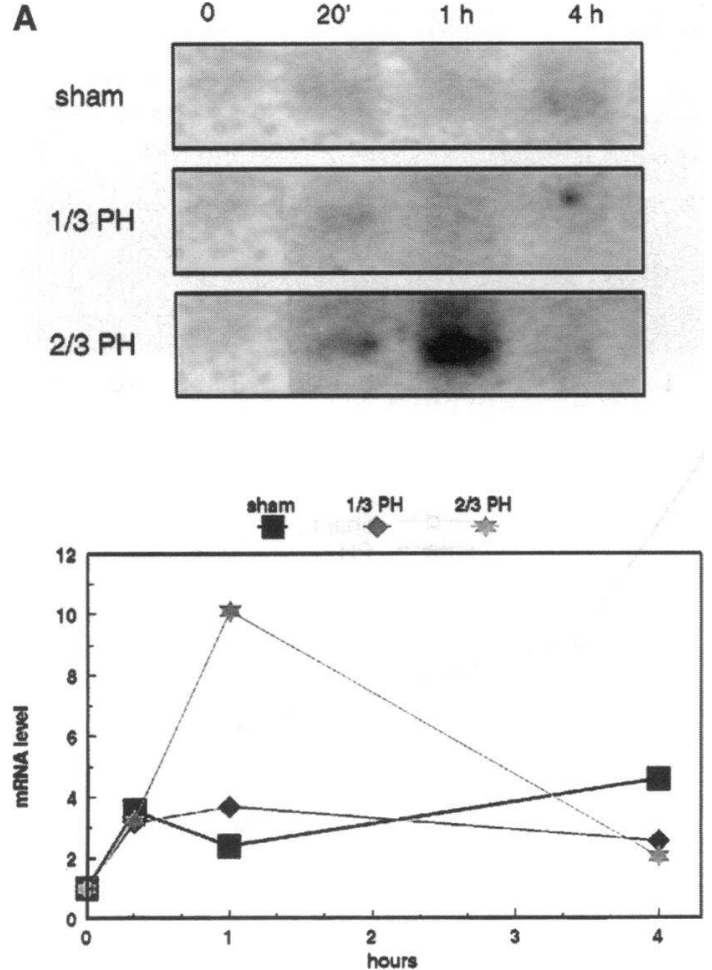

C
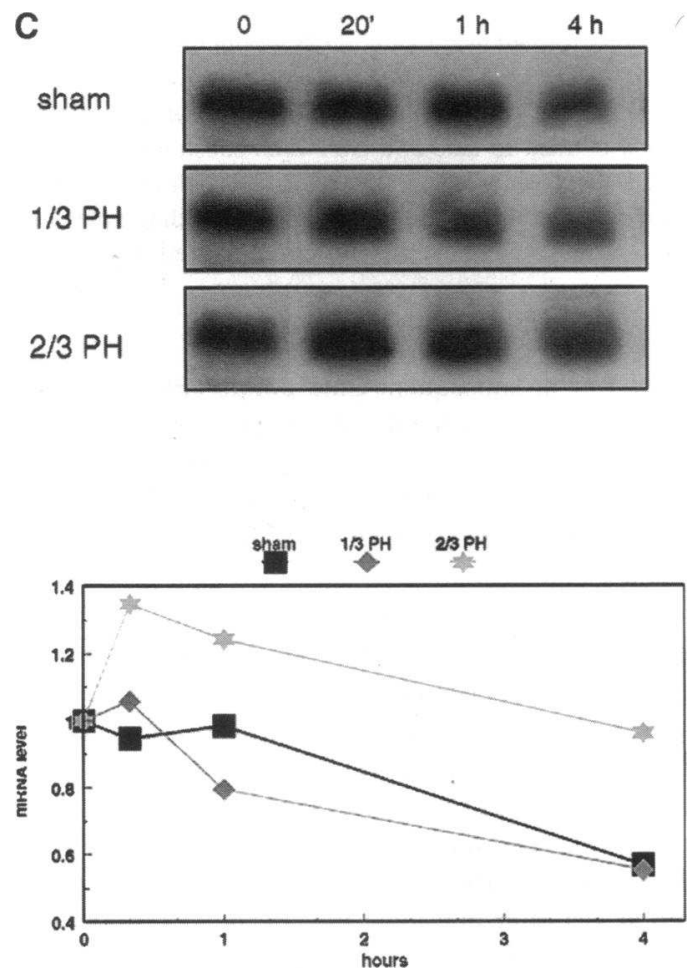

B



$1 / 3 \mathrm{PH}$

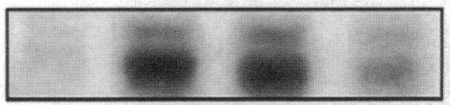

$2 / 3 \mathrm{PH}$
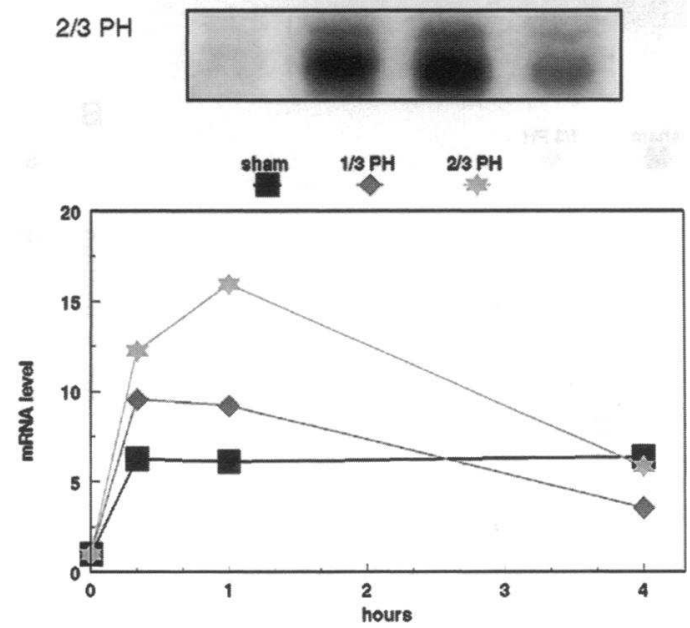

Figure 1. Hepatic mRNA levels after one-third and two-thirds PH. Autoradiograms are shown of Northern blots of hepatic total RNA hybridized with probes for $f o s$ $(A)$, c-jun $(B)$, and albumin $(C)$. Each lane represents RNA from one animal. In comparison with the $18 \mathrm{~S}$ and $28 \mathrm{~S}$ ribosomal RNAs, the molecular sizes of the mRNAs are $\sim 2.2 \mathrm{~kb}$ for $\mathrm{c}-f o s, 2.7$ and $3.0 \mathrm{~kb}$ for c-jun, and $2.5 \mathrm{~kb}$ for albumin.

PH, 10-fold by one-third $\mathrm{PH}$, and 6-fold by sham operation. Albumin mRNA levels (Fig. $1 C$ ) are slightly changed by the surgical operations and serve as controls for mRNA integrity.

To assess the contribution of c-Jun protein to the AP-1 transcription complex in the liver, a series of mobility shift assays were performed using an AP-1-binding site as the probe and nuclear extracts prepared from sham or one-third PH livers (Fig. 2). In the sham-operated animals, there is induction of
AP-1 binding activity, with a maximal increase of fivefold compared with control $(T=0)$ animals (Fig. $2 A$ ). In the onethird $\mathrm{PH}$ animals, there is a greater stimulation of AP-1 binding activity at time points after $20 \mathrm{~min}$, with a 13-fold stimulation achieved at $4 \mathrm{~h}$ (Fig. $2 \mathrm{~A}$ ). The constituents of the AP- $1 \mathrm{com}$ plex were assessed using a specific antibody against c-Fos or c-Jun. The anti-c-Fos antibody disrupted the AP-1 complex in the one-third $\mathrm{PH}$ extracts at $20 \mathrm{~min}$ only, and not in control 
A

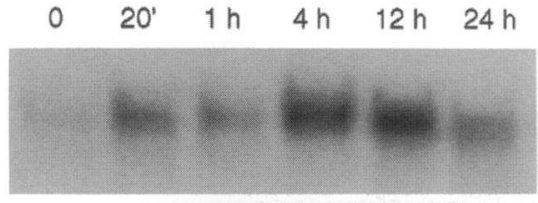

$1 / 3 \mathrm{PH}$
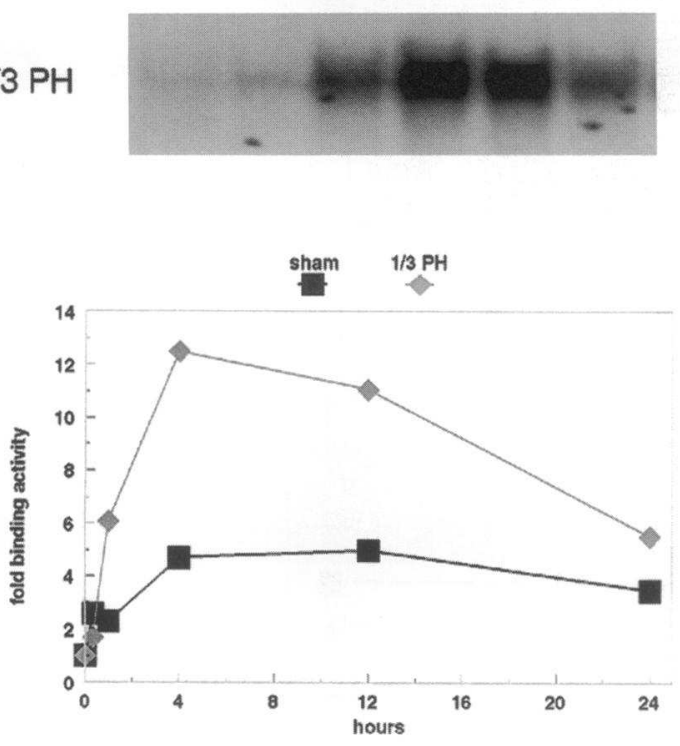

B

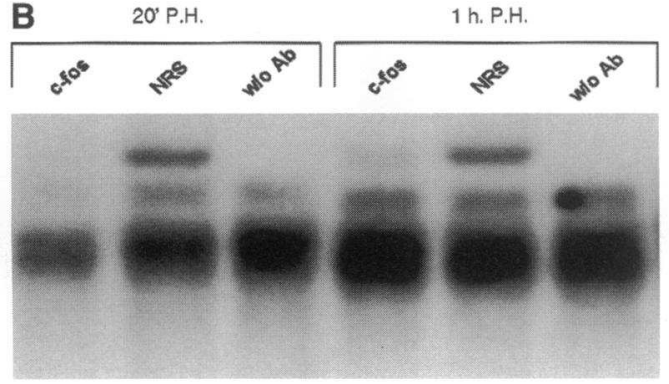

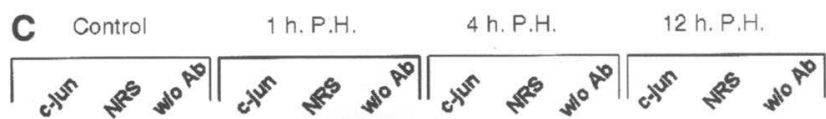

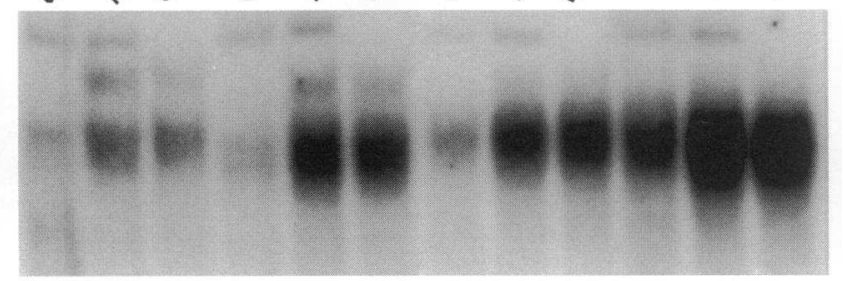

Figure 2. AP-1 binding activity of nuclear extracts is induced after onethird PH and contains Jun and Fos proteins. $(A)$ Time course of AP-1 binding activity after one-third $\mathrm{PH}$ or sham operation. Extracts prepared at the indicated times were incubated with a radiolabeled double-strand DNA probe representing a consensus AP-1-binding site, incubated at room temperature for $20 \mathrm{~min}$, and fractionated on $4 \%$ nondenaturing polyacrylamide gels. Shifted complexes were visualized by autoradiography (top) or quantitated by phosphorimage analysis (bottom). (B) Incubations with the indicated extracts were performed as previously described, with the addition of $1 \mu \mathrm{l}$ of normal rabbit serum (NRS), 1 $\mu \mathrm{l}$ of c-Fos-specific antisera (c-fos), or with no addition ( $w / o A b)$ for an additional $15-\mathrm{min}$ incubation at $37^{\circ} \mathrm{C}$. $(C)$ Incubations with probe and the indicated extracts were performed as previously described, with the addition of $0.5 \mu \mathrm{l}$ of normal rabbit serum (NRS), $0.5 \mu \mathrm{l}$ of c-Junspecific antisera $(c$-jun $)$, or with no addition $(w / o A b)$ for $15 \mathrm{~min}$ at $37^{\circ} \mathrm{C}$.
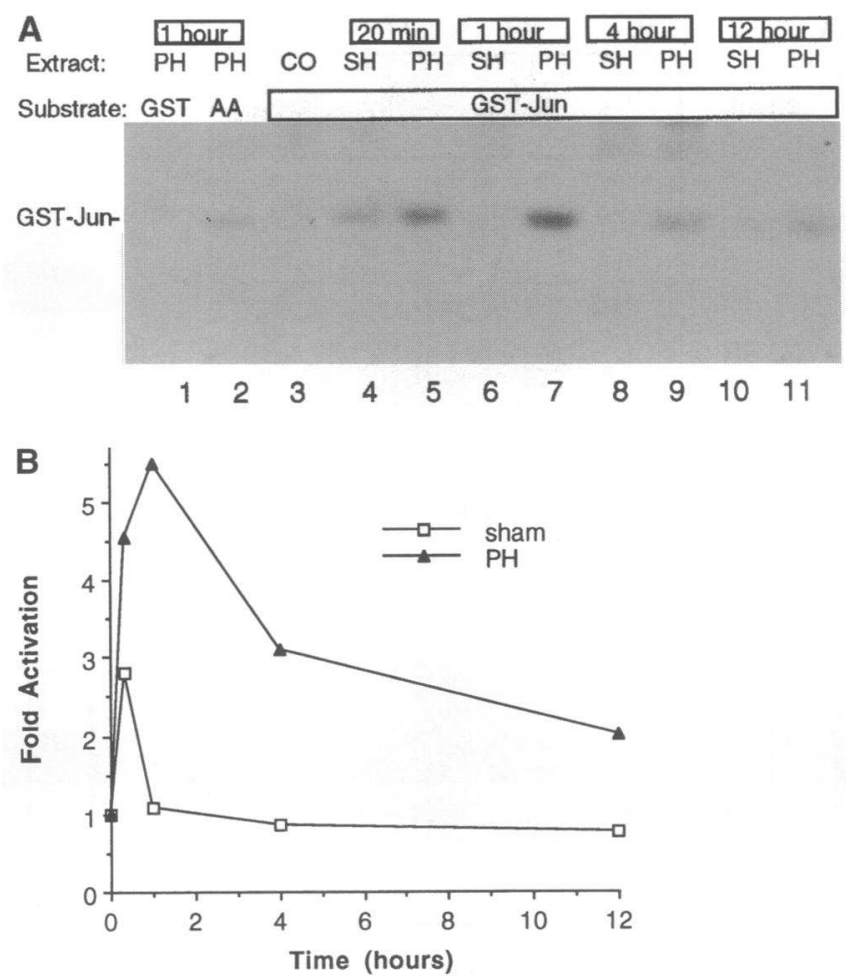

Figure 3. JNK activity is induced after PH. ( $A$ ) Solid-phase in vitro kinase assays were performed using $1 \mu \mathrm{g}$ of GST-cJun linked to agarose as a substrate and $50 \mu \mathrm{g}$ of the indicated hepatic nuclear extracts as the kinase source. In lane 1 , a non-fusion GST protein was incubated with the 1-h PH nuclear extract. In lane 2, a GST-cJun substrate mutated at Ser-63 and Ser-73 (GST-cJun(AA)) was incubated with the 1-h PH extract. Phosphorylated proteins were detected by autoradiography. $(B)$ Quantitation of $A$ was by scintillation counting of excised bands.

(data not shown) or at subsequent time points (Fig. $2 \mathrm{~B}$, and data not shown). On the other hand, anti-c-Jun antiserum inhibited the formation of the AP-1 complex in control $(\mathrm{T}=0)$ nuclear extracts and at $1 \mathrm{~h}$ and $4 \mathrm{~h}$ after one-third $\mathrm{PH}$. By 12 $\mathrm{h}$ after $\mathrm{PH}$, the anti-c-Jun antiserum only partially disrupted the AP-1 complex (Fig. $2 C$ ).

Previous studies have demonstrated that c-Jun is modified by phosphorylation at several sites $(15-19,37)$. Therefore, we assessed the ability of these hepatic nuclear extracts to phosphorylate the c-Jun activation domain in an in vitro kinase assay. Using the same hepatic nuclear extracts as those discussed, onethird PH results in a marked increase in the activity of a nuclear kinase that phosphorylates the c-Jun activation domain (Fig. 3 $A$ and $B$ ). The peak activity (greater than fivefold over sham levels) is seen at $1 \mathrm{~h}$ after one-third PH. In the sham-operated livers, JNK activity is minimally stimulated at $20 \mathrm{~min}$ and unstimulated at $1 \mathrm{~h}$. As controls, GST protein and GST-cJun(AA) (in which Ser-63 and Ser-73 are replaced by Ala) are used as substrates in this assay (Fig. $3 \mathrm{~A}$, lanes 1 and 2 ).

To characterize this JNK activity further, an immune complex kinase assay was performed. Antisera raised against recombinant JNK1 protein (21) were used to precipitate a kinase source from the same nuclear extracts. Extracts prepared from livers $1 \mathrm{~h}$ and $4 \mathrm{~h}$ after one-third $\mathrm{PH}$ display increased kinase activity specific for the c-Jun activation domain when compared with the same time points in sham-operated or control animals (Fig. $4 A$ ). Thus JNK1 or an immunologically related kinase 


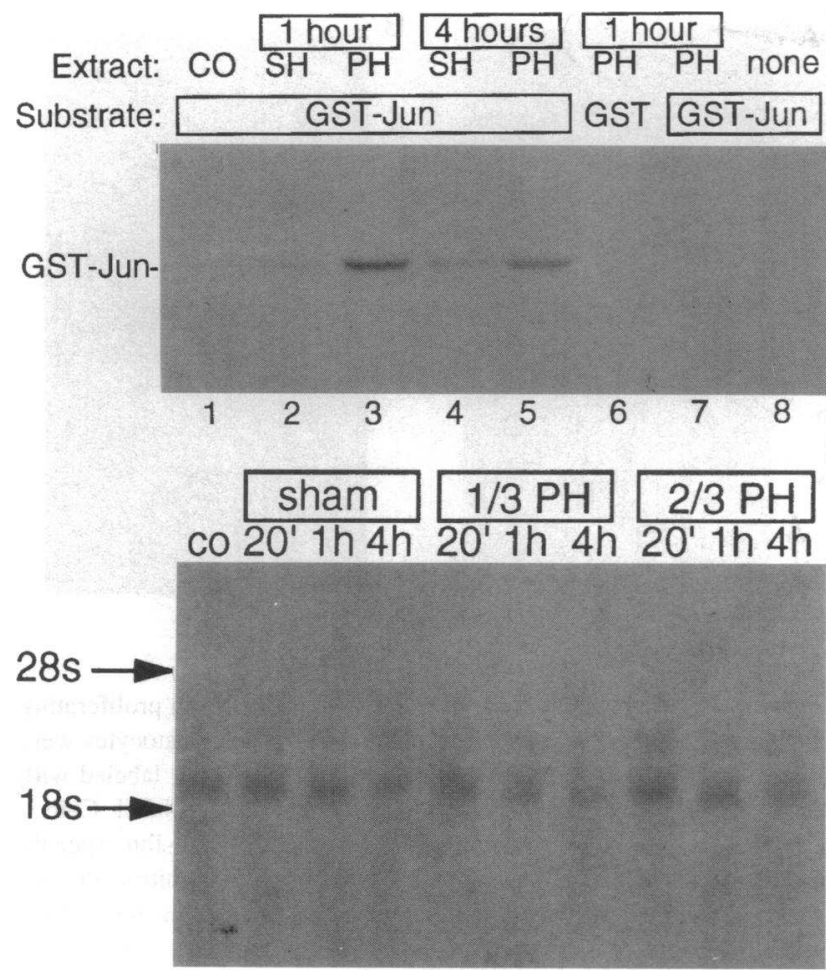

Figure 4. (A) JNK1 activity is induced after one-third PH. Immune complex kinase assays were performed using the indicated liver extracts immunoprecipitated with antisera raised against JNK1. Complexes were washed extensively and used as the kinase source in an in vitro kinase assay with GST-cJun as the substrate (lanes $1-5,7$, and 8 ). Non-fusion GST protein was used as control (lane 6). No phosphorylation of the substrate was seen without the addition of antibody (lane 7) or extract (lane 8). (B) Northern blot of total hepatic RNA from control ( $c o$ ), sham-operated (sham), one-third $\mathrm{PH}$, or two-thirds $\mathrm{PH}$ animals probed with a JNK1 cDNA. Migration of the $18 \mathrm{~S}$ and $28 \mathrm{~S}$ ribosomal bands is indicated.

is induced following $\mathrm{PH}$ with kinetics similar to that seen in the whole nuclear extract. A Northern blot of RNA from control, sham-operated, one-third $\mathrm{PH}$, and two-thirds $\mathrm{PH}$ animals, probed with a JNK1 cDNA (21), reveals no significant increases in the mRNA levels of one prominent and one minor transcript (Fig. $4 B$ ). The slight decrease in JNK-1 mRNA levels at $4 \mathrm{~h}$ after PH might contribute to the subsequent decrease in JNK-1 activity (Fig. $4 \mathrm{~B}$ ).

To gain insight into the regulation of the AP-1 transcription factors in the proliferating hepatocytes, we performed studies using primary cultures of adult rat hepatocytes. In the first set of experiments we used primary cultures of adult rat hepatocytes that are quiescent upon prolonged culture and in which proliferation is reinduced upon the addition of hepatic mitogens (25). In this culture system, the hepatic mitogen TGF $\alpha$ stimulates cjun mRNA levels (25) and stimulates a luciferase reporter gene driven by the c-jun promoter, which itself contains an AP-1binding site (Jun-Luc; Fig. $5 \mathrm{~A}$ ). To assess directly the role of the c-Jun transactivation domain in the stimulation of AP-1 transcriptional activity in hepatocytes, we used a chimeric protein containing the c-Jun transactivation domain linked in frame to the Gal4 DNA-binding domain. The potency of the transactivation by this chimeric protein is assessed by the cotransfection of a reporter gene containing five binding sites for the Gal4 protein into the cultured hepatocytes. After transfection, incu-
A


C



Figure 5. Jun activation in primary cultures of adult rat hepatocytes. $(A)$ Primary hepatocytes plated on plastic dishes were transfected with a c-Jun promoter-luciferase reporter gene (Jun-Luc) and allowed to become quiescent for $4 \mathrm{~d}$. Cells were left unchanged, or subjected to medium change with or without the addition of TGF $\alpha(10 \mathrm{ng} / \mathrm{ml}) .12$ $h$ later, extracts were assayed for luciferase activity and protein content. $(B)$ Primary hepatocytes were transfected with the 5XGal-Luc reporter and Gal4-cJun, Gal4-cJun(AA), or the cognate empty expression vectors. $4 \mathrm{~d}$ later, EGF ( $10 \mathrm{ng} / \mathrm{ml})$ or PBS alone was added to the media, and luciferase activity and protein concentrations were determined $5 \mathrm{~h}$ later. Fold activation represents the activity of the indicated expression vectors over the reporter activity in the presence of the empty expression vector, normalized for protein content. $(C)$ Primary hepatocytes were plated on collagen type IV-coated plates and transfected with the indicated reporter genes and expression vectors as previously described. 24 $h$ after transfection, defined medium with EGF $(10 \mathrm{ng} / \mathrm{ml})$ or vehicle (PBS) was added, and luciferase activity was determined $24 \mathrm{~h}$ later. Results are expressed as fold activation normalized for protein content as previously described. All graphs represents the results of two to four experiments performed in duplicate. 
bating hepatocytes with the hepatic mitogen EGF stimulates the expression of the reporter gene fourfold (Fig. $5 \mathrm{~B}$ ). On the other hand, after cotransfection of a chimeric protein containing a mutated c-Jun transactivation domain in which Ser-63 and Ser-73 are mutated to Ala, no stimulation by EGF was seen. These experiments demonstrate that EGF enhances transcription of c-Jun through its activation domain and requires these two phosphorylation target sites.

Using a different culture system in which freshly isolated hepatocytes are plated onto type IV collagen, the hepatocytes are already proliferating (38). Transfections into these hepatocytes demonstrate that EGF further activates AP-1-driven transcription, as demonstrated by stimulation of the 2XTRE-luc reporter gene, which contains four AP-1 -binding sites. Furthermore, the wild type but not mutant Gal4-cJun chimera exhibits increased stimulation of the 5XGal-Luc reporter gene in the presence of EGF (Fig. $5 C$ ). Therefore, two separate methods for culturing rat hepatocytes demonstrate increased activation of AP-1-dependent transcription after mitogen treatment and, in particular, a role for the c-Jun activation domain in this enhanced activity.

Finally, we assessed c-Jun phosphorylation in 2-d-old hepatocyte cultures plated on plastic. Previous studies $(39,40)$ have demonstrated that during this time the cells are transiting from the lag to log phase of growth. The cultured hepatocytes were incubated with $\left[{ }^{32} \mathrm{P}\right]$ orthophosphate and left untreated or treated with EGF for the final 30 min before cell lysis. c-Jun protein was then immunoprecipitated, gel purified, and trypsinized. Twodimensional phosphopeptide maps demonstrate that the c-Jun is phosphorylated on its $\mathrm{NH}_{2}$-terminal activation domain at Ser63 and Ser-73, as indicated by the intense labeling of the $\mathrm{X}$ and Y phosphopeptides (Fig. $6 A$ ). Densitometry reveals that EGF treatment (Fig. $6 \mathrm{~B}$ ) increases the phosphorylation of these amino-terminal peptides by $200 \%$. Phosphorylation of peptides adjacent to the DNA-binding domain ( $A, B$, and $C$, Fig. 6) increase to a lesser extent with EGF treatment, such that the ratio of amino-terminal to carboxy-terminal peptide phosphorylation is increased by $40 \%$ after EGF treatment. Carboxy-terminal phosphorylation is consistent with phosphorylation of at least one of these sites by mitogen-activated protein kinases $(41,42)$, which are activated by EGF in other cultured cells $(22$, 43). Therefore, c-Jun is phosphorylated on its amino-terminal activation domain in proliferating cultured hepatocytes. We have never observed significant phosphorylation of the activation domain in quiescent cells (43, and unpublished observations ).

\section{Discussion}

This study is consistent with a model in which one-third $\mathrm{PH}$ results in stimulation of JNK activity, phosphorylation of the c-Jun activation domain, and increased transcription of genes with AP-1 sites. After one-third PH (this study) or two-thirds PH (24), one of the earliest biochemical changes we have observed is the stimulation of JNK activity. The decrease in the mobility of the hepatic c-Jun protein after PH is consistent with the phosphorylation of its activation domain (data not shown). When primary cultures of adult rat hepatocytes are treated with mitogens, the phosphorylation of the c-Jun activation domain is increased, resulting in enhanced transcriptional activity of c-Jun and increased transcription of genes containing AP-1 binding sites.

Previous studies have demonstrated that a variety of factors
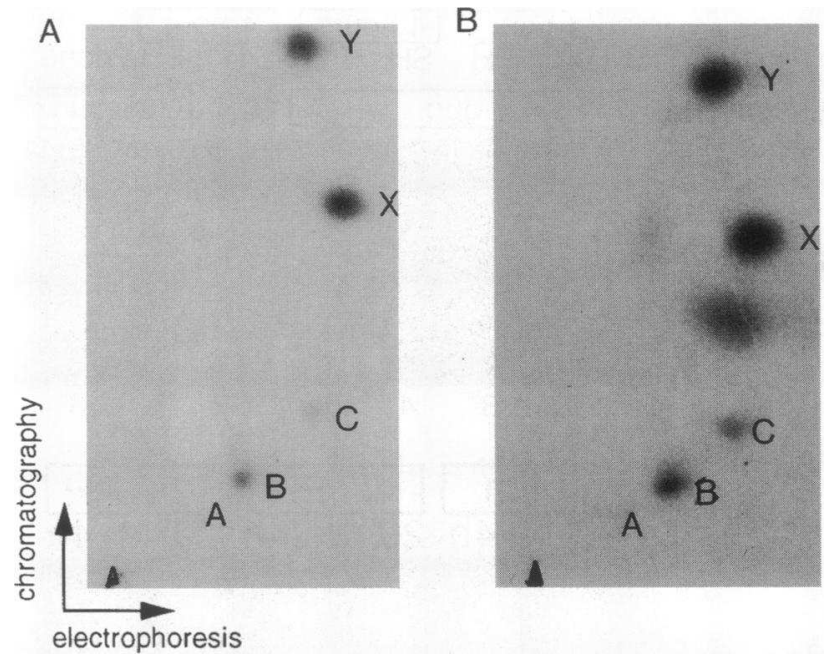

Figure 6. c-Jun is phosphorylated on Ser-63 and Ser-73 in proliferating hepatocytes. $100-\mathrm{mm}$ tissue culture plates of primary hepatocytes were transfected with a c-jun expression vector and, $24 \mathrm{~h}$ later, labeled with $1 \mathrm{mCi} / \mathrm{ml}\left[{ }^{32} \mathrm{P}\right]$ orthophosphate or $150 \mu \mathrm{Ci} / \mathrm{ml}$ Trans $-{ }^{35} \mathrm{~S}-$ label. Cells were lysed in RIPA buffer and immunoprecipitated with c-Jun-specific antisera. After electrophoresis and transfer of proteins to nitrocellulose c-Jun was eluted, trypsinized, and subjected to two-dimensional phosphopeptide mapping. Electrophoresis was in the horizontal dimension (left to right) and phosphochromatography in the vertical dimension. (A) Map from proliferating hepatocytes. $(B)$ Map from proliferating hepatocytes treated with EGF for $30 \mathrm{~min}$. Peptide spots labeled $X$ and $Y$ contain Ser-73 and Ser-63, respectively. Spots labeled $A, B$, and $C$ correspond to peptides adjacent to the DNA-binding domain of c-Jun (15).

sensitize the liver to regenerative stimuli. Sensitizing or priming factors include protein starvation (44), thyroidectomy (45), choline deficiency (46), alloxan-induced diabetes mellitus (47), and one-third PH (9). Biochemical changes that underlie this sensitization or priming event are unclear. However, mitogens such as EGF and TGF $\alpha$, which stimulate initiation of DNA synthesis in quiescent hepatocyte cultures (25), induce several changes that are possible candidates, including ion fluxes, $\mathrm{Na}^{+} /$ $\mathrm{K}^{+}$ATPase, and induction of c-fos and c-jun $(2,5,48)$. This study demonstrates that an early event associated with sensitization or priming is the activation of c-Jun amino-terminal kinase activity (JNK), and, in particular, the activation of the kinase JNK1 or an immunologically cross-reacting kinase. JNK activity is induced by $20 \mathrm{~min}$ and peaks at $1 \mathrm{~h}$ after one-third $\mathrm{PH}$, and JNK1-specific activity also peaks at $1 \mathrm{~h}$. The activation of JNK, which does not require de novo protein synthesis or gene transcription, might be responsible for initiating and maintaining the stimulation of the AP-1 transcription factor.

Our studies demonstrate a proportional increase in AP-1 activity between sham operation, one-third PH, and two-thirds $\mathrm{PH}$, as assessed by c-jun mRNA levels, AP-1 binding activity, overall JNK activity, and JNK1 activity. For example, the maximal increase in JNK activity compared with control is 2.8 -fold following sham operation, 5.5-fold following one-third $\mathrm{PH}$, and 11.9-fold following two-third PH. Previous studies in mice (2) have also demonstrated a progressive stimulation of hepatic cfos mRNA levels from sham operation, $15 \% \mathrm{PH}, 50 \% \mathrm{PH}$, and $70 \% \mathrm{PH}$. Differences between the present study and previous studies, which showed either more (2) or less (9) effect of sham operation on activation of AP-1 factors, might reflect 
differences in the sensitivity of the assays, the method of sham operation, or the strain of rat. Our sham operation, consisting of anesthesia, laparotomy, manipulation of the liver, surgical closure of the abdomen, and anesthesia recovery, reflects the stimulus of a normal surgical procedure. Regardless, sensitization or priming does not appear to represent an all or nothing event, but rather a continuum of increased stimulation of critical biochemical events, including the activation of JNK.

The AP-1 transcription factors are a family of proteins that form specific heterodimers or homodimers (49). Analysis of AP-1 binding activity in the liver after $\mathrm{PH}$ demonstrates the contribution of c-Fos to the complex only early during PH (20 min after one-third PH). On the other hand, c-Jun is a major constituent of the AP-1-binding complex in the quiescent liver and through $4 \mathrm{~h}$ after PH. By $12 \mathrm{~h}$ after PH, c-Jun still contributes to the AP-1 complex, but other proteins are predominant. These results are consistent with previous studies which report that Jun-B/LRH-1 heterodimers increase late during hepatic regeneration ( 8 ) and may be the major constituents at $12 \mathrm{~h}$.

This study used primary cultures of adult rat hepatocytes to study functional aspects of the AP-1 transcription factor that were not amenable to in vivo experiments. Using reporter gene transfections into two different hepatocyte culture systems (plating on plastic or type IV collagen), we demonstrated that the hepatic mitogens EGF and TGF $\alpha$ stimulate AP-1 transcriptional activity. In particular, EGF stimulates the c-Jun activation domain. This enhanced transcriptional activity correlates with the phosphorylation of the c-Jun activation domain, in agreement with previous studies in immortal cell lines. An indirect assay for the JNK activity responsible for this phosphorylation is the ratio of the Gal4-Luc reporter gene activity elicited by Gal4-cJun (stimulated by phosphorylation) compared with Gal4-cJun(AA) (not sensitive to phosphorylation because of mutations). Using this assay, we found that the plastic-plated hepatocytes have lower basal JNK activity that is more EGF inducible than the type IV collagen-plated hepatocytes. Thus, together the in culture and in vivo results support a model in which stimulation of hepatic JNK activity results in increased c-Jun phosphorylation, enhanced AP-1 transcriptional activity, and increase expression of AP-1-containing genes.

Previous studies have revealed multiple factors that activate JNK activity in cultured cells (20-22, 37, 43, 50). Ultraviolet light is the most potent inducer of JNK activity $(20,21)$. Transforming oncogenes, including oncogenic Ras and Raf, will stimulate JNK activity $(17-19,36)$, and there is a direct correlation between Ras transforming activity and c-Jun activation (36). Finally, TNF $\alpha$ and, to lesser extent, EGF increase JNK activity $(22,43)$. TNF $\alpha$ appears to stimulate JNK through a pathway that is independent of Ras, Raf, or extracellular signal-regulated kinase (ERK) activation (43). The initial mediator that activates JNK after one-third PH is unknown. However, we have recently demonstrated that a neutralizing antibody to TNF $\alpha$ abolishes the activation of JNK (24) and hepatic regeneration after two-thirds $\mathrm{PH}(24,51)$. On the basis of the aforementioned data, TNF $\alpha$ is a potential candidate for the agonist that stimulates in a paracrine manner the early stimulation of JNK activity during hepatic regeneration.

In addition to multiple specific pathways leading to JNK activity, recent evidence suggests that a family of closely related kinases may be involved. JNK1, the first member of this family to be cloned, is a $46-\mathrm{kD}$ ultraviolet- and Ras-stimulated kinase $(20,21)$ that mediates at least part of the TNF $\alpha$-stimulated JNK activity in fibroblasts (43). Several related proteins, called stress-activated protein kinases (SAPKs), which share $90 \%$ identity, have subsequently been cloned (22). One of these (SAPK $\gamma)$ represents an alternately spliced form of JNK1 (21, 22). All of these kinases are proline-directed serine/threonine kinases and are related to ERKs 1 and 2. However, as they share only $\sim 40 \%$ homology with the ERKs, they are not functionally interchangeable. The ERKs and JNKs (or SAPKs) participate in different pathways and have different substrate specificities $(21,22,43,52)$. Although proteins recognized by anti-JNK1 antiserum have increased kinase activity after $\mathrm{PH}$, there is no change in mRNA levels recognized by a JNK1 cDNA probe. This is reminiscent of the stimulation of ERK 1 and 2 activity during proliferation, in which activity is induced despite unchanged mRNA and protein levels (53).

The unique role of c-Jun in hepatic proliferation is reflected in the failure of liver development in a c-Jun knock-out mouse (13). Our study demonstrates that hepatocyte priming includes the activation of JNK. The subsequent phosphorylation of the c-Jun activation domain results in the activation of a preformed transcription factor, which appears to be one of the earliest and most sensitive changes preceding hepatic regeneration. Therefore, JNK activity, which has previously been characterized in immortal cell lines, is stimulated in vivo after $\mathrm{PH}$.

\section{Acknowledgments}

This work was supported by National Institutes of Health grants GM41084, DK34987, and CA50528 (to D. A. Brenner) and DK28215 (to H. L. Leffert); by University of California Tobacco Related Disease Research Program grant 4RT0076 (to H. L. Leffert); and by US Academic Senate grant RT96-M (to H. L. Leffert). We thank A. Minden and $\mathrm{M}$. Karin for providing reagents and for helpful discussions.

\section{References}

1. Alcorn, J. M., S. P. Feitelberg, and D. A. Brenner. 1990. Transient induction of c-Jun during hepatic regeneration. Hepatology. 11:909-915.

2. Kruijer, W., H. Skelly, F. Botteri, H. Van Der Puten, J. R. Barber, I Verma, and H. L. Leffert. 1986. Proto-oncogene expression in regenerating liver is simulated in cultures of primary adult rat hepatocytes. J. Biol. Chem. 261:79297933.

3. Thompson, N. L., J. E. Mead, L. Braun, M. Goyette, P. R. Shank, and N. Fausto. 1986. Sequential protooncogene expression during rat liver regeneration. Cancer Res. 46:3111-3117.

4. Coni, P., G. Simbula, A. Carcerri de Prati, M. Menegazzi, H. Suzuki, D. S. R. Sarma, G. M. Ledda-Columbano, and A. Columbano. 1993. Differences in the steady-state levels of c-fos, c-jun and c-myc messenger RNA during mitogeninduced liver growth and compensatory regeneration. Hepatology. 17:1109-1116.

5. Koch, K. S., and H. L. Leffert. 1979. Increased sodium ion influx is necessary to initiate rat hepatocyte proliferation. Cell. 18:153-163.

6. Morello, D., M. J. Fitzgerald, C. Babinet, and N. Fausto. 1990 c-myc, c-fos, and c-jun regulation in the regenerating livers of normal and $\mathrm{H}$ 2K/c-myc transgenic mice. Mol. Cell. Biol. 10:3185-3193.

7. Makino, R., K. Hayashi, and T. Sugimura. 1984. c-myc transcript is induced in rat liver at a very early stage of regeneration or by cycloheximide treatment Nature (Lond.). 310:697-698.

8. Hsu, J.-C., R. Bravo, and R. Taub. 1992. Interactions among LRF-1, JunB, c-Jun, and c-Fos define a regulatory program in the $\mathrm{g} 1$ phase of liver regeneration. Mol. Cell. Biol. 12:4654-4665.

9. Webber, E. M., P. J. Godowski, and N. Fausto. 1994. In vivo response of hepatocytes to growth factors requires an initial priming stimulus. Hepatology. 14:489-497.

10. Minuk, G. Y., T. Gauthier, and A. Benarroch. 1990. Changes in serum and hepatic polyamine concentrations after $30 \%, 70 \%$ and $90 \%$ partial hepatectomy in rats. Hepatology. 12:542-546.

11. Angel, P., M. Imagawa, R. Chiu, B. Stein, R. J. Imbra, H. J. Rahmsdorf, C. Jonat, P. Herrlich, and M. Karin. 1987. Phorbol ester-inducible genes contain a common cis element recognized by a TPA-modulated trans-acting factor. Cell. 49:729-739.

12. Angel, P., and M. Karin. 1991. The role of Jun, Fos and the AP-1 complex in cell proliferation and transformation. Biochim. Biophys. Acta. 1072:129-157. 
13. Hilberg, F. A., A. Aguzzi, N. Howells, and E. F. Wagner. 1993. c-Jun is essential for normal mouse development and hepatogenesis. Nature (Lond.). 365:179-181.

14. Angel, P., K. Hattori, T. Smeal, and M. Karin. 1988. The jun protooncogene is positively autoregulated by its product, Jun/AP-1. Cell. 55:875-885.

15. Boyle, W. J., T. Smeal, L. H. K. Defize, P. Angel, J. R. Woodgett, M. Karin, and T. Hunter. 1991. Activation of protein kinase C decreases phosphorylation of c-Jun at sites that negatively regulate its DNA-binding activity. Cell. 64:573-584.

16. Lin, A., J. Frost, T. Deng, T. Smeal, N. Al-Alawi, U. Kikkawa, T. Hunter, D. Brenner, and M. Karin. 1992. Casein kinase II is a negative regulator of c-Jun DNA binding and AP-1 activity. Cell. 70:1-20.

17. Binetruy, B., T. Smeal, and M. Karin. 1991. Ha-ras augments c-Jun activity and stimulates phosphorylation of its activation domain. Nature (Lond.). 351:122-127.

18. Smeal, T., B. Binetruy, D. A. Mercola, M. Birrer, and M. Karin. 1991. Oncogenic and transcriptional cooperation with $\mathrm{Ha}$-Ras requires phosphorylation of c-Jun on serines 63 and 73. Nature (Lond.). 354:494-496.

19. Smeal, T., B. Binetruy, D. Mercola, A. Grover-Bardwick, G. Heidecker, U. R. Rapp, and M. Karin. 1992. Oncoprotein-mediated signalling cascade stimulates c-Jun activity by phosphorylation of serines 63 and 73. Mol. Cell. Biol. 12:3507-3513.

20. Hibi, M., A. Lin, T. Smeal, A. Minden, and M. Karin. 1993. Identification of an oncoprotein and UV-responsive protein kinase that binds and potentiates the c-Jun activation domain. Genes Dev. 7:2135-2148.

21. Derijard, B., M. Hibi, I.-H. Wu, T. Barrett, B. Su, T. Deng, M. Karin, and R. J. Davis. 1994. JNK1: a protein kinase stimulated by UV light and HaRas that binds and phosphorylates the c-Jun activation domain. Cell. 76:10251038

22. Kyriakis, J. M., P. Banerjee, E. Nikolakaki, T. Dai, E. A. Ruble, M. F. Ahmad, J. Avruch, and J. R. Woodgett. 1994. The stress-activated protein kinase subfamily of c-Jun kinases. Nature (Lond.). 369:156-160.

23. Leffert, H. L., K. S. Koch, T. Moran, and B. Rubalcava. 1979. Hormonal control of rat liver regeneration. Gastroenterology. 76:1470-1482.

24. Diehl, A. M., M. Yin, J. Fleckenstein, S. Q. Yang, H. Z. Lin, D. A. Brenner, J. Westwick, G. Bagby, and S. Nelson. 1994. Tumor necrosis factor $\alpha$ initiates and localizes the regenerative response to liver injury. Am. J. Physiol. 267:G552-562.

25. Brenner, D. A., K. S. Koch, and H. L. Leffert. 1989. Transforming growth factor- $\alpha$ stimulates proto-oncogene c-jun expression and a mitogenic program in primary cultures of adult rat hepatocytes. DNA. 8:279-285.

26. Hattori, M., A. Tugores, J. Westwick, L. Veloz, H. L. Leffert, M. Karin, and D. A. Brenner. 1993. Activation of activating protein 1 during hepatic acute phase response. Am. J. Physiol. 264:G95-G103.

27. van Beveren, C., F van Straaten, T Curran, $R$. Müller, and I. M. Verma. 1983. Analysis of FBJ-MuSV provirus and c-fos (mouse) gene reveals that viral and cellular $f$ os gene products have different carboxy termini. Cell. 32:12411255.

28. Sargent, T. D., M. Yang, and J. Bonner. 1981. Nucleotide sequence of cloned rat serum albumin messenger RNA. Proc. Natl. Acad. Sci. USA. 78:243246.

29. Hattori, M., A. Tugores, M. Karin, and D. A. Brenner. 1990. A simplified method for the preparation of nuclear extracts. DNA. 9:777-781.

30. Smith, S. B., and K. S. Johnson. 1988. Single-step purification of polypeptides expressed in E. coli as fusions with glutathione S-transferase. Gene. 67:3140.

31. Cereghini, S., M. Blumenfeld, and M. Yaniv. 1988. A liver specific factor essential for albumin transcription differs between differentiated and dedifferentiated rat hepatoma cells. Genes Dev. 2:957-974.

32. Gardner, A. M., C. A. Lange-Carter, R. R. Vaillancourt, and G. L. Johnson. 1993. Measuring the activation of kianses in the MAP kinase regulatory network. Methods Enzymol. In press.

33. Rippe, R. A., D. A. Brenner, and H. L. Leffert. 1990. DNA-mediated gene transfer into adult rat hepatocytes in primary culture. Mol. Cell. Biol. 10:689695.
34. Pasco, D. S., and J. B. Fagan. 1989. Efficient DNA-mediated gene transfer into cultures of adult rat hepatocytes. DNA. 8:535-541.

35. Kreamer, B. L., J. L. Staecker, N. Sawada, G. L. Sattler, M. T. S. Hsia, and H. C. Pitot. 1986. Use of a low speed, iso-density Percoll centrifugation method to increase the viability of isolated rat hepatocyte preparations. In Vitro Cell. Dev. Biol. 22:210-211.

36. Westwick, J. K., A. D. Cox, C. J. Der, M. H. Cobb, M. Hibi, M. Karin, and D. A. Brenner. 1994. Oncogenic Ras activates c-Jun via a separate pathway from the activation of extracellular-signal regulated kinases. Proc. Natl. Acad. Sci. USA. 91:6030-6034.

37. Adler, V., C. C. Franklin, and A. S. Kraft. 1992. Phorbol esters stimulate the phosphorylation of c-Jun but not v-Jun: regulation by the $\mathrm{N}$-terminal $\partial$ domain. Proc. Natl. Acad. Sci. USA. 89:5341-5345.

38. Mischoulon, D., B. Rana, N. L. R. Bucher, and S. R. Farmer. 1992. Growth-dependent inhibition of CCAAT enhancer-binding protein (C/EBP $\alpha$ ) gene expression during hepatocyte proliferation in the regenerating liver and in culture. Mol. Cell. Biol. 12:2553-2560.

39. Leffert, H. L., T. Moran, S. Sell, H. Skelly, K. Ibsen, M. Mueller, and I. Arias. 1978. Growth state dependent phenotypes of adult hepatocytes in primary monolayer culture. Proc. Natl. Acad. Sci. USA. 75:1834-1838.

40. Brown, J. W., P. J. Lad, H. Skelly, K. S. Koch, M. Lin, and H. Leffert. 1983. Expression of differentiated function by hepatocytes in primary culture: variable effects of glucagon and insulin on gluconeogenesis during cell growth. Differentiation. 25:176-184.

41. Chou, S. Y., V. Baichwal, and J. L. Ferrell, Jr. 1992. Inhibition of c-Jun DNA binding by mitogen-activated protein kinase. Mol. Biol. Cells. 3:11171130.

42. Alvarez, E., I. C. Norhtwood, F. A. Gonzalez, D. A. Latour, A. Seth, C. Abate, T. Curran, and R. Davis. 1991. Pro-Leu-Ser/Thr-Pro is a consensus primary sequence for substrate protein phosphorylation. J. Biol. Chem. 266:1527715285.

43. Westwick, J. K., C. Weitzel, A. Minden, M. Karin, and D. A. Brenner. 1994. Tumor necrosis factor $\alpha$ stimulates AP-1 activity through prolonged activation of the c-Jun kinase. J. Biol. Chem. 269:26396-26401.

44. Leduc, E. H. 1949. Mitotic activity in the liver of the mouse during inanition followed by re-feeding with different levels of protein. Am. J. Anat. $84: 397-430$

45. Short, J., R. T. Brown, A. Husakous, J. R. Gilbertson, R. Zemel, and I Lieberman 1972. Induction of DNA synthesis in the liver of the intact animal. J. Biol. Chem. 247:1757-1766.

46. Leffert, H. L., and K. S. Koch. 1971. Control of animal cell proliferation. In Growth, Nutrition and Metabolism of Cells in Culture. G. H. Rothblat and V. J. Cristofalo, editors. Academic Press Inc., New York/London/San Francisco. 225-294.

47. Younger, L. R., J. King, and D. F. Steiner. 1966. Hepatic proliferative response to insulin in severe alloxan diabetes. Cancer Res. 26:1408-1414.

48. Schenk, D. B., J. J. Hubert, and H. L. Leffert. 1984. Use of monoclonal antibody to quantify [ $\mathrm{Na}, \mathrm{K}]-\mathrm{ATPase}$ activity and sites in normal and regenerating rat liver. J. Biol. Chem. 259:14941-14951.

49. Karin, M. 1991. The AP-1 complex and its role in transcriptional control by protein kinase C. In The Hormonal Control Regulation of Gene Transcription. P. Cohen and J. G. Foulkes, editors. Elsevier Science Publishing Co. Inc., New York. 235-253.

50. Franklin, C. C., P. Unlap, D. Adler, and A. S. Kraft. 1993. Multiple signa transduction pathways mediate c-Jun protein phosphorylation. Cell Growth Differ. 4:377-385.

51. Akerman, P., P. Cote, S. Q. Yang, C. McClain, S. Nelson, G. J. Bagby, and A. M. Diehl. 1992. Antibodies to tumor necrosis factor-alpha inhibit liver regeneration after partial hepatectomy. Am. J. Physiol. 263:G579-G585.

52. Su, B., E. Jacinto, M. Hibi, T. Kallunki, M. Karin, and Y. Ben-Neriah 1994. JNK is involved in signal integration during costimulation of $\mathrm{T}$ lymphocytes. Cell. 77:727-736.

53. Robbins, D. J., E. Zhen, M. Cheng, S. Xu, C. A. Vanderbilt, D. Ebert, C. Garcia, A. Dang, and M. H. Cobb. 1993. Regulation and properties of extracellular signal-regulated protein kinases 1, 2, and 3. J. Am. Soc. Nephrol. 4:1104-1110. 